\title{
Individualized Catheter Surveillance among Neonates: A Prospective, 8-Year, Single-Center Experience
}

\author{
Walter Zingg, MD; Klara M. Posfay-Barbe, MD; Riccardo E. Pfister, MD; \\ Sylvie Touveneau, RN; Didier Pittet, MD, MS
}

\begin{abstract}
овJECTIVE. To monitor trends in central line-associated bloodstream infections and clinical sepsis (CLABICS) among neonates and to determine risk factors for infection, especially dwell time.
\end{abstract}

DESIGN. Prospective, single-center cohort study conducted from 2001 through 2008.

SETTING. University-affiliated tertiary care center.

мЕтноDs. Individualized surveillance of catheter use and CLABICS episodes was conducted. Data were obtained via regular on-site visits made 3 times a week. Trends over time were estimated by Poisson regression, and risk factor analysis was conducted using a Cox proportional hazards model and logistic regression.

REsults. In all, 1,124 neonates were exposed to 2,210 central lines for a total of 12,746 catheter-days and 11,467 catheter-days at risk. The median duration of catheter use was 8 (interquartile range, 5-11) days for peripherally inserted central catheters (PICCs) and 4 (interquartile range, 2-6) days for umbilical catheters; 102 CLABICS episodes were detected. The median time to infection was 7 days. Incidence densities were 8.5 CLABICS episodes per 1,000 catheter-days at risk and 8.0 CLABICS episodes per 1,000 catheter-days. The highest rates were identified among neonates weighing $750 \mathrm{~g}$ or lower (14.9 CLABICS episodes per 1,000 catheter days at risk) and for PICCs (13.2 CLABICS episodes per 1,000 catheter days at risk). Catheter dwell time was associated with CLABICS for all umbilical catheters (odds ratio $[\mathrm{OR}], 1.2$ per day of use $[95 \%$ confidence interval $\{\mathrm{CI}\}, 1.1-1.3] ; \mathrm{P}<.001)$ and for PICCs for up to 7 days $(\mathrm{OR}, 1.2$ [95\% CI, 1.1-1.4]; $P=.041$ ), but not thereafter (OR, $1.0[95 \% \mathrm{CI}, 0.9-1.1] ; P=.90)$.

CONCLUsion. Catheter dwell time is a risk factor for CLABICS during the first 7 days, irrespective of catheter type. After 7 days, PICCs are less likely to become infected.

Infect Control Hosp Epidemiol 2010; 32(1):42-49

Healthcare-associated infections (HAIs) are the leading preventable adverse events in critically ill patients and are associated with considerable morbidity, mortality, and use of additional resources. ${ }^{1,2}$ Neonates, particularly preterm infants with a very low birth weight or extremely low birth weight, are at high risk for HAIs, with reported rates ranging from 6 to 9 episodes per 1,000 patient-days. ${ }^{3-5}$ In contrast to adults, among whom the proportion of bloodstream infections and sepsis is only approximately $5 \%-8 \%,{ }^{6-8}$ in neonates bloodstream infections may represent up to three-quarters of all HAIs. ${ }^{9-18}$

The objectives of the present study were to assess secular trends for central line-associated bloodstream infections and clinical sepsis (CLABICS), to determine risk factors for CLABICS in peripherally inserted central catheters (PICCs) and umbilical catheters, and to place our findings in the context of the available literature.

\section{METHODS}

Setting

A prospective cohort study was conducted from April 1,2001, through December 31, 2008, at the University of Geneva Hospitals (Geneva, Switzerland), a 2,100-bed university-affiliated primary and tertiary care center that has a 20-bed neonatal intensive care unit (NICU) and an 8-bed pediatric intensive care unit (PICU). Neonates were hospitalized in the PICU if they needed ventilation. In 2001, we established an ongoing, prospective HAI surveillance program for neonates. ${ }^{19}$ All neonates with a central line (PICC or umbilical

\footnotetext{
From the Infection Control Program (W.Z., S.T., D.P.) and the Department of Pediatrics (K.M.P.-B., R.E.P.), University of Geneva Hospitals and Faculty of Medicine, Geneva, Switzerland.

Received March 23, 2010; accepted July 7, 2010; electronically published November30, 2010.

(C) 2010 by The Society for Healthcare Epidemiology of America. All rights reserved. 0899-823X/2011/3201-0006\$15.00. DOI: 10.1086/657634
} 
TABLE 1. Catheter Dwell Times Stratified by Birth Weight Category among Neonates-University of Geneva Hospitals, 2001-2008

\begin{tabular}{lccccc}
\hline & \multicolumn{2}{c}{ All catheters } & & \multicolumn{2}{c}{ Umbilical catheters } \\
\cline { 2 - 3 } \cline { 5 - 6 } Birth weight category & $\begin{array}{c}\text { Mean (SD) } \\
\text { dwell time, days }\end{array}$ & $\begin{array}{c}\text { Median (IQR) } \\
\text { dwell time, days }\end{array}$ & $\begin{array}{c}\text { Mean (SD) } \\
\text { dwell time, days }\end{array}$ & $\begin{array}{c}\text { Median (IQR) } \\
\text { dwell time, days }\end{array}$ \\
\hline$\leqslant 750 \mathrm{~g}$ & $8.2(5.9)$ & $7(4-11)$ & & $5.8(3.7)$ & $5(3-8)$ \\
$751-1,000 \mathrm{~g}$ & $7.0(5.0)$ & $6(4-9)$ & & $4.5(2.2)$ & $4(3-6)$ \\
$1,001-1,500 \mathrm{~g}$ & $6.1(3.9)$ & $5(3-8)$ & & $4.3(2.8)$ & $4(2-6)$ \\
$1,501-2,500 \mathrm{~g}$ & $4.7(3.1)$ & $4(3-6)$ & & $3.8(2.2)$ & $4(2-5)$ \\
$>2,500 \mathrm{~g}$ & $4.1(3.2)$ & $3(2-5)$ & & $3.6(2.0)$ & $3(2-5)$ \\
Trend $^{\mathrm{a}}$ & $-4.4 \%$ & & $-4.5 \%$ & \\
$P$ value $^{2.001}$ & $<.001$ & & & $<.001$ & \\
\hline
\end{tabular}

NOTE. IQR, interquartile range; $\mathrm{SD}$, standard deviation.

a Mean change in dwell time per birth weight category.

catheter) were prospectively included in the study; there was no exclusion criterion for neonates with a central line.

\section{Surveillance}

The same infection control nurse visited the NICU and PICU 3 times a week for on-site surveillance during the entire study period. ${ }^{19}$ Each neonate included in the study was prospectively monitored, and data on such variables as birth weight, Clinical Risk Index for Babies (CRIB) score, Apgar score, and gestational age were collected. ${ }^{20,21}$ Each PICC, umbilical artery catheter, and umbilical venous catheter was monitored individually during the entire life span of the device. Neonates with long-term tunneled central venous catheters were excluded from the study. HAIs were identified via medical record review, an automated alert system for positive blood culture results, participation by the infection control nurse in ward rounds, direct information from physicians and nursing staff, direct observation of neonates, and complete review of laboratory reports. ${ }^{19,22}$

\section{Definitions}

The occurrence of CLABICS, defined as laboratory-confirmed bloodstream infection or clinical sepsis, was the primary end point. Clinical sepsis was included as an outcome parameter because blood culture samples from neonates are often not reliable, and thus ignoring clinical sepsis would underestimate the true rate of bloodstream infection. ${ }^{22-24}$ CLABICS episodes were defined according to the US Centers for Disease Control and Prevention (CDC) criteria. ${ }^{25,26}$ All infections were confirmed by a neonatologist (R.E.P.) or an infectious diseases and infection control physician (K.M.P.-B. or W.Z.). A CLABICS episode was considered to be associated with health care if diagnosed 3 days or more after birth. Dwell time was defined as the number of full days a catheter was in place.

\section{Statistical Analysis}

Crude analysis was conducted by analyzing CLABICS episodes on the basis of the total number of catheter-days or patient-days, respectively. ${ }^{27}$ For risk analysis, only the first CLABICS episodes were considered; they were analyzed on the basis of the number of catheter-days or patient-days at risk. At-risk days were defined as catheter-days or patientdays before a CLABICS episode. Subsequent days and subsequent catheters were excluded from the analysis. Exposure to parenteral nutrition and antibiotics was included in the risk analysis if present before a CLABICS episode. Continuous variables were summarized as means and medians and were compared by the Student $t$ test or the Wilcoxon rank sum test, as appropriate. A Cox proportional hazards model was used to investigate the association between the time at risk of developing CLABICS and various variables, such as birth weight, gestational age, parenteral nutrition, antibiotic use, and CRIB score. We modeled time to event in a single-event analysis in which the unit of analysis was the catheter. Because a neonate could have more than 1 catheter either at the same time or sequentially, we adjusted for intragroup correlation by specifying each neonate as a cluster. ${ }^{28,29}$ We first investi-

TABLE 2. Pathogens Isolated from Central Line-Associated Bloodstream Infections among Neonates-University of Geneva Hospitals, 2001-2008

\begin{tabular}{lc}
\hline Pathogen & $\begin{array}{c}\text { Frequency } \\
(n=69)\end{array}$ \\
\hline Staphylococcus epidermidis & $30(43.5)$ \\
Other coagulase-negative staphylococci & $17(24.6)$ \\
Staphylococcus capitis & $6(8.7)$ \\
Escherichia coli & $6(8.7)$ \\
Enterococcus species & $4(5.8)$ \\
Methicillin-susceptible Staphyloccocus & $2(2.9)$ \\
$\quad$ aureus & \\
Methicillin-resistant S. aureus & $1(1.5)$ \\
Streptococcus viridans & $1(1.5)$ \\
Enterobacter cloacae & $1(1.5)$ \\
Klebsiella pneumoniae & $1(1.5)$ \\
\hline
\end{tabular}

NOTE. Data are no. (\%) of pathogens. Thirty-three infections were clinical sepsis episodes. 
TABLE 3. Incidence Densities (IDs) for Central Line-Associated Bloodstream Infections and Clinical Sepsis (CLABICS) among Neonates, Overall and by Birth Weight and Catheter Type-University of Geneva Hospitals, 2001-2008

\begin{tabular}{|c|c|c|c|}
\hline Category & $\begin{array}{c}\text { No. of } \\
\text { CLABICS episodes }\end{array}$ & $\begin{array}{l}\text { Days of } \\
\text { exposure }\end{array}$ & ID $(95 \% \mathrm{CI})$ \\
\hline & \multicolumn{3}{|c|}{ Overall } \\
\hline Patient-days & 102 & 46,173 & $2.2(1.8-2.7)$ \\
\hline Patient-days at risk & 97 & 24,048 & $4.0(3.3-4.9)$ \\
\hline Catheter-days & 102 & 12,764 & $8.0(6.5-9.7)$ \\
\hline \multirow[t]{2}{*}{ Catheter-days at risk } & 97 & 11,467 & $8.5(6.9-10.3)$ \\
\hline & \multicolumn{3}{|c|}{ CLABICS episodes per 1,000 catheter-days } \\
\hline \multicolumn{4}{|l|}{ Birth weight category } \\
\hline$\leqslant 750 \mathrm{~g}$ & 28 & 2,062 & $13.6(9.0-19.6)$ \\
\hline $751-1,000 \mathrm{~g}$ & 34 & 2,700 & $12.6(8.7-17.6)$ \\
\hline $1,001-1,500 \mathrm{~g}$ & 30 & 3,916 & $7.7(5.2-10.9)$ \\
\hline $1,501-2,500 \mathrm{~g}$ & 7 & 2,169 & $3.2(1.3-6.6)$ \\
\hline$>2,500 \mathrm{~g}$ & 3 & 1,917 & $1.6(0.3-4.6)$ \\
\hline \multicolumn{4}{|l|}{ Catheter type } \\
\hline PICCs & 80 & 6,909 & $11.6(9.2-14.4)$ \\
\hline UACs & 3 & 1,528 & $2.0(0.4-5.7)$ \\
\hline \multirow[t]{2}{*}{ UVCs } & 19 & 4,327 & $4.4(2.6-6.8)$ \\
\hline & \multicolumn{3}{|c|}{ CLABICS episodes per 1,000 catheter-days at risk } \\
\hline \multicolumn{4}{|l|}{ Birth weight category } \\
\hline$\leqslant 750 \mathrm{~g}$ & 25 & 1,681 & $14.9(9.6-21.9)$ \\
\hline $751-1,000 \mathrm{~g}$ & 33 & 2,215 & $14.9(10.3-20.9)$ \\
\hline $1,001-1,500 \mathrm{~g}$ & 29 & 3,583 & $8.1(5.4-11.6)$ \\
\hline $1,501-2,500 \mathrm{~g}$ & 7 & 2,095 & $3.3(1.3-6.9)$ \\
\hline$>2,500 \mathrm{~g}$ & 3 & 1,893 & $1.6(0.3-4.6)$ \\
\hline \multicolumn{4}{|l|}{ Catheter type } \\
\hline PICCs & 75 & 5,664 & $13.2(10.4-16.6)$ \\
\hline UACs & 3 & 1,508 & $2.0(0.4-5.8)$ \\
\hline UVCs & 19 & 4,295 & $4.4(2.7-6.9)$ \\
\hline
\end{tabular}

NOTE. CI, confidence interval; PICCs, peripherally inserted central catheters; UACs, umbilical artery catheters; UVCs, umbilical venous catheters.

gated all potential risk factors by univariate analysis. Variables with a $P$ value of less than .02 were included in the multivariate analysis. $P$ values less than .05 were considered to indicate statistical significance, and only variables meeting this criterion were retained in the final model. Time trends were estimated by Poisson regression. Logistic regression analysis was used to quantify the association with catheter dwell time (measured as the number of catheter-days with a CLABICS episode) and to distinguish between catheter types related to such a risk. Similar to the strategy for the Cox proportional hazards model, we adjusted for intragroup correlation by specifying each neonate as a cluster, and integration of variables in the multivariate analysis was done accordingly. All statistical analyses were conducted with Stata software, version 10.0 (StataCorp).

\section{RESULTS}

\section{Patient Characteristics}

From 2001 through 2008, 3,772 neonates were hospitalized, totaling 46,173 patient-days. Of these neonates, $1,124(30 \%)$ had 1 or more central vascular access devices and were included in the study. The median gestational age of the neonates was 32 (interquartile range [IQR], 29-37) weeks. Most neonates were singletons (894 [80\%]); 492 (44\%) had a very low birth weight, and 205 (18\%) had an extremely low birth weight. Mean and median CRIB scores were 3.3 (standard deviation $[\mathrm{SD}], 3.8)$ and $2(\mathrm{IQR}, 1-5)$, respectively. Mean and median birth weights were $1,943(\mathrm{SD}, 1,012)$ and 1,660 (IQR, 1,130-2,730) g, respectively. The median Apgar score after 5 minutes was 9 (IQR, 7-9). The total length of stay was 29,646 


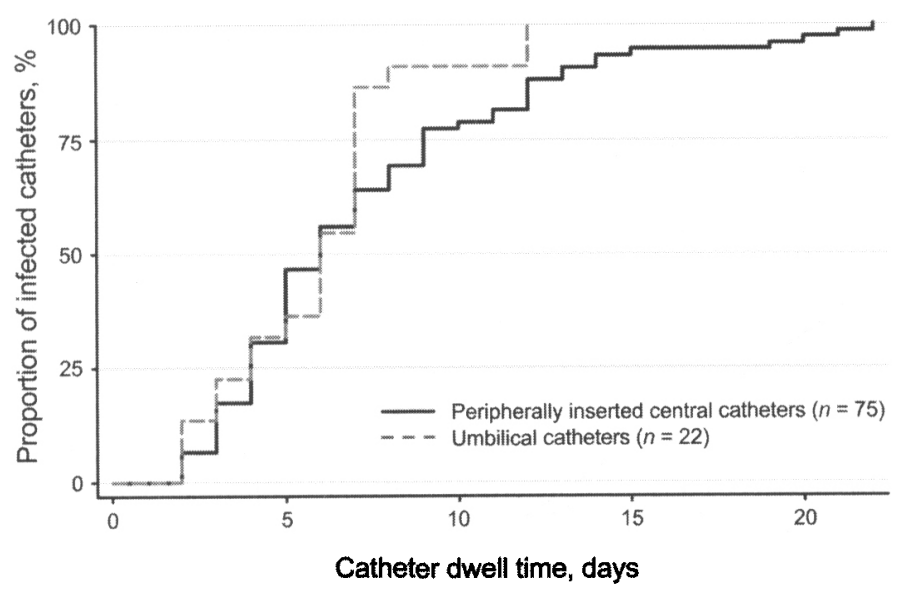

FIGURE 1. Time to infection for peripherally inserted central catheters and umbilical catheters among neonates-University of Geneva Hospitals, 2001-2008.

days, with a mean of $26.6(\mathrm{SD}, 27.2)$ days and a median of 17 (IQR, 8-37) days, respectively. A total of 24,048 days $(81 \%)$ were patient-days at risk. There were significant trends over time toward lower birth weights $(P<.001)$ but also toward a shorter length of stay $(P=.001)$.

\section{Central Lines}

A total of 2,210 central lines accounting for 12,764 catheterdays were observed among the 1,124 neonates (utilization. rate, $27.6 \%[12,764$ of 46,173$])$. A total of 2,116 catheters (723 PICCs [34.2\%], 385 umbilical artery catheters [18.2\%], and 1,008 umbilical venous catheters [47.6\%]) accounting for 11,467 catheter-days at risk were included in the risk analysis. The mean and median dwell times at risk were 7.8 (SD, 4.7) and 8 (IQR, 5-11) days for PICCs, 3.9 (SD, 2.5) and 3 (IQR, 2-5) days for umbilical artery catheters, and 4.3 (SD, 2.5) and 4 (IQR, 2-6) days for umbilical venous catheters, respectively. Dwell times differed significantly between
PICCs and umbilical catheters (median, 7 [IQR, 5-10] vs 4 [IQR, 2-5] days; $P<.001$ ). Catheter dwell times depended significantly on birth weight categories (Table 1). Neonates weighing $750 \mathrm{~g}$ or less had PICCs in place twice as long as neonates weighing more than $2,500 \mathrm{~g}$. Similarly, umbilical dwell times were also significantly shorter among neonates in the highest birth weight category than the lowest (median, 3 [IQR, 2-5] vs 5 [IQR, 3-8] days; $P<.001$ ). Parenteral nutrition and intravenous antibiotics were applied through $1,115(53 \%)$ and $1,341(61 \%)$ catheters, respectively. During the time at risk, 1,034 catheters $(49 \%)$ were used for parenteral nutrition, and 1,205 (57\%) were used for antibiotic therapy.

\section{CLABICS}

A total of 102 CLABICS episodes were observed (laboratoryconfirmed bloodstream infections, 69; clinical sepsis episodes, 33). Most isolated pathogens (77\%) were coagulase-negative

TABLE 4. Risk Factors for Central Line-Associated Bloodstream Infections and Clinical Sepsis among Neonates-University of Geneva Hospitals, 2001-2008

\begin{tabular}{lcrlllr}
\hline & \multicolumn{2}{c}{ Univariate analysis } & & \multicolumn{2}{c}{ Multivariate analysis } \\
\cline { 2 - 3 } Variable & HR $(95 \% \mathrm{CI})$ & \multicolumn{1}{c}{$P$} & & HR $(95 \% \mathrm{CI})$ & $P$ \\
\hline Catheter type $^{\mathrm{a}, \mathrm{b}}$ & $0.75(0.56-1.01)$ & .063 & & \\
Extremely low birth weight $^{\mathrm{b}}$ & $2.11(1.40-3.19)$ & $<.001$ & & $2.24(1.42-3.53)$ & .001 \\
Pluriparity $^{\mathrm{b}}$ & $1.67(1.10-2.55)$ & .016 & & \\
Apgar score $^{\mathrm{b}}$ & $0.99(0.99-0.99)$ & .003 & & \\
CRIB score $^{\text {Calendar year }}$ & $1.02(0.98-1.07)$ & .359 & & \\
Parenteral nutrition $^{\mathrm{b}}$ & $0.97(0.89-1.05)$ & .462 & & .027 \\
Antibiotic use $^{\mathrm{b}, \mathrm{c}}$ & $2.92(1.46-5.82)$ & .002 & $2.23(1.10-4.55)$ & \\
\hline
\end{tabular}

Nоте. CI, confidence interval; CRIB, Clinical Risk Index for Babies; HR, hazard ratio.

a Umbilical catheters vs peripherally inserted central catheters.

${ }^{b}$ Included in the multivariate analysis.

${ }^{c}$ Intravenous antibiotic use at any time over the central line. 
TABLE 5. Benchmarking of Bloodstream Infections and Clinical Sepsis among Neonates at the University of Geneva Hospitals with the German Hospital Infection Surveillance System (KISS) and the US National Healthcare Safety Network (NHSN)

\begin{tabular}{|c|c|c|c|c|c|c|}
\hline \multirow[b]{2}{*}{ Category } & \multicolumn{3}{|c|}{ Geneva data } & \multicolumn{3}{|c|}{ Comparison data } \\
\hline & $\begin{array}{c}\text { No. of } \\
\text { CLABICS } \\
\text { episodes }\end{array}$ & $\begin{array}{c}\text { No. of } \\
\text { catheter-days }\end{array}$ & ID $(95 \% \mathrm{CI})$ & $\begin{array}{c}\text { No. of } \\
\text { CLABICS } \\
\text { episodes }\end{array}$ & $\begin{array}{c}\text { No. of } \\
\text { catheter-days }\end{array}$ & ID $(95 \% \mathrm{CI})$ \\
\hline & \multicolumn{6}{|c|}{ Geneva data vs KISS data ${ }^{a}$} \\
\hline \multicolumn{7}{|l|}{ Birth weight } \\
\hline$<1,000 \mathrm{~g}$ & 61 & 4,569 & $13.4(10.2-17.1)$ & 661 & 52,467 & $12.6(11.7-13.6)$ \\
\hline $1,000-1,499 \mathrm{~g}$ & 30 & 3,993 & $7.5(5.1-10.7)$ & 170 & 22,277 & $7.6(6.5-8.9)$ \\
\hline \multirow[t]{2}{*}{ All } & 91 & 8,562 & $10.6(8.6-13.0)$ & 831 & 74,744 & $11.1(10.4-11.9)$ \\
\hline & \multicolumn{6}{|c|}{ Geneva data vs NHSN data, ${ }^{\mathrm{b}}$ central lines } \\
\hline \multicolumn{7}{|l|}{ Birth weight } \\
\hline$\leqslant 750 \mathrm{~g}$ & 19 & 1,248 & $15.2(9.1-23.7)$ & 225 & 60,850 & $3.7(3.2-4.2)$ \\
\hline $751-1,000 \mathrm{~g}$ & 31 & 1,772 & $17.5(11.9-24.7)$ & 185 & 55,445 & $3.3(2.9-3.9)$ \\
\hline $1,001-1,500 \mathrm{~g}$ & 24 & 2,447 & $9.8(6.3-14.6)$ & 144 & 55,874 & $2.6(2.2-3.0)$ \\
\hline $1,501-2,500 \mathrm{~g}$ & 5 & 930 & $5.4(1.7-12.5)$ & 105 & 44,402 & $2.4(1.9-2.9)$ \\
\hline$>2,500 \mathrm{~g}$ & 1 & 512 & $2.0(0.0-10.8)$ & 87 & 42,611 & $2.0(1.6-2.5)$ \\
\hline \multirow[t]{2}{*}{ All } & 80 & 6,909 & $11.6(9.2-14.4)$ & 746 & 259,182 & $2.9(2.7-3.1)$ \\
\hline & \multicolumn{6}{|c|}{ Geneva data vs NHSN data, ${ }^{b}$ umbilical lines } \\
\hline \multicolumn{7}{|l|}{ Birth weight } \\
\hline$\leqslant 750 \mathrm{~g}$ & 9 & 814 & $11.1(5.1-21.0)$ & 79 & 16,762 & $4.7(3.7-5.9)$ \\
\hline $751-1,000 \mathrm{~g}$ & 3 & 928 & $3.2(0.7-9.4)$ & 39 & 15,034 & $2.6(1.8-3.5)$ \\
\hline $1,001-1,500 \mathrm{~g}$ & 6 & 1,469 & $4.1(1.5-8.9)$ & 32 & 16,681 & $1.9(1.3-2.7)$ \\
\hline $1,501-2,500 \mathrm{~g}$ & 2 & 1,239 & $1.6(0.2-5.8)$ & 15 & 16,321 & $0.9(0.5-1.5)$ \\
\hline$>2,500 \mathrm{~g}$ & 2 & 1,405 & $1.4(0.2-5.1)$ & 22 & 22,978 & $1.0(0.6-1.4)$ \\
\hline All & 22 & 5,855 & $3.8(2.4-5.7)$ & 187 & 87,776 & $2.1(1.8-2.5)$ \\
\hline
\end{tabular}

NOTE. Incidence densities (IDs) are reported as the no. of central line-associated bloodstream infections and clinical sepsis (CLABICS) episodes per 1,000 catheter-days. CI, confidence interval.

a Pooled mean data from KISS.

$b$ Pooled mean data from NHSN.

staphylococci, of which Staphylococcus epidermidis was identified the most frequently (Table 2). The overall incidence densities for CLABICS were 8.0 episodes per 1,000 catheterdays and 8.5 episodes per 1,000 catheter-days at risk (Table 3 ). The incidence densities for laboratory-confirmed central line-associated bloodstream infection with and without cases of clinical sepsis were 8.0 episodes per 1,000 catheter-days and 5.4 episodes per 1,000 catheter-days, respectively. No statistically significant trend in CLABICS rates over the total study period was observed. Of note, the observed incidence of infection depended largely on the denominator chosen to calculate it (Table 3 ). The incidence density varied according to birth weight and catheter type; neonates with a low birth weight and/or a PICC rather than an umbilical line had higher CLABICS rates (Table 3 ).

The median time to a CLABICS episode for PICCs and umbilical catheters was 7 (IQR, 5-10) and 7 (IQR, 5-8) days, respectively (Figure 1 ). Time to infection diminished significantly over the course of the study, by a mean of $5.4 \%$ per year (from 9.9 [SD, 5.1] days in 2001 to 7.1 [SD, 3.1] days in 2008; $P<.001)$. The time from admission to infection also diminished significantly, by a mean of $5.0 \%$ per year (from 15.5 [SD, 10.0] days in 2001 to 9.9 [SD, 4.1] days in 2008; $P<.001$ ). As shown in Figure 1, time-to-infection curves are identical for PICCs and umbilical catheters, assuming that dwell time is a similar risk factor for both catheter types.

\section{Risk Factors}

The occurrence of CLABICS among all catheter types was independently associated with extremely low birth weight $(P=.001)$ and exposure to total parenteral nutrition $(P=$ .027) (Table 4). A significant reduction in the number of CLABICS episodes was observed when antibiotics were administered through the catheter $(P<.001)$. Catheter dwell time expressed as adjusted risk per catheter-day was signifcantly associated with CLABICS in the logistic regression analysis (odds ratio [OR], 1.1 per day of use $[95 \%$ confidence interval $\{\mathrm{CI}\}, 1.0-1.1] ; P=.005$ ). Adjustments were made for extremely low birth weight, exposure to parenteral nutrition, and antibiotic therapy. For umbilical catheters, the adjusted risk was significant for all catheters (OR, 1.2 per day 
of use [95\% CI, 1.1-1.3]; $P<.001)$. However, for PICCs the adjusted risk was significant for a dwell time of up to 7 days (OR, 1.2 per day of use [95\% CI, 1.1-1.4]; $P=.041$ ), but not thereafter $(\mathrm{OR}, 1.0$ per day of use [95\% CI, 0.9-1.1]; $P=.90)$.

\section{DISCUSSION}

This single-center prospective cohort study includes data recorded at the individual patient level for 8 years and is the largest and longest of its kind, to the best of our knowledge. The study reveals statistically significant reductions in catheter dwell times over the years, confirms the importance of known risk factors for CLABICS (such as low birth weight and parenteral nutrition ${ }^{30-32}$ ), and highlights the unanticipated finding that for PICCs dwell time is statistically significantly associated with CLABICS during the first 7 days, but not thereafter.

Although prolonged catheter dwell time among neonates has been repeatedly associated with CLABICS, ${ }^{33-35}$ a recent study even found an opposite trend for PICCs. ${ }^{36}$ Our data do not completely contradict these data but add another perspective to the findings: whereas there was a statistically significant association between dwell time and CLABICS for umbilical catheters, such an association was significant for PICCs for only up to 7 days of dwell time. The median time to infection was identical for umbilical catheters and PICCs. Because the dwell time of only $10 \%$ of umbilical catheters exceeded 7 days, it is no surprise that the dwell time for this catheter type as a whole was associated with CLABICS, whereas for PICCs overall no such association was observed. Our data show that longer dwell times for PICCs are associated with either antibiotic therapy (OR, 1.1 [95\% CI, 1.11.2]; $P<.001$ ) or parenteral nutrition (OR, 1.2 [95\% CI, 1.1$1.31 ; P<.001)$. Given that longer catheterization is more likely to be associated with antibiotic use $(P<.001)$, which in turn is associated with fewer CLABICS episodes, it is no surprise that the incidence density for CLABICS was lower among PICCs with a longer duration ( $>7$ days). However, our data support the hypothesis that the daily risk for CLABICS changes with dwell time, being highest within 7 days of placement but decreasing thereafter. This is most likely due to the indications for PICC use in this context, especially the use of antibiotics. Our data suggest that the routine replacement of PICCs is not advisable. Although we found increased daily risk during the first days of placement, our results are in line with those of a study by Smith et al ${ }^{36}$ that found no association at all. However, more information is needed before any firm recommendation can be made, and future studies should also compare PICCs with peripheral catheters to verify whether PICCs may be replaced by peripheral lines.

Only a few studies have reported data on time to infection. ${ }^{37,38}$ Ben Jaballah et a ${ }^{38}$ found a mean of 6.6 (SD, 2.8) days to infection for all catheter types; Hoang et $\mathrm{al}^{37}$ reported a median time of 9 days for PICCs of the upper extremities, although the median time was longer (15 days) for PICCs of the lower extremities. Our findings are consistent with these data. Importantly, we observed that time to infection was similar among all catheter types. The decrease in time to infection in our population, however, is worrying. Prolonged time to infection has been shown to be a favorable indicator for good catheter care. ${ }^{28}$ Thus, observing the opposite trend may indicate that issues regarding the quality of catheter care exist in our NICU. Of note, prolonged time to infection could also be associated with the observed changes in case mix.

A key obstacle of HAI reporting is the varying modes of outcome definition and denominator selection. Using the example of ventilator-associated pneumonia, Eggimann et al ${ }^{27}$ showed that the method of reporting pneumonia rates has a significant effect on risk estimates. The incidence density doubled when rates were adjusted by ventilator-days at risk instead of patient-days in intensive care. Our study data are even more pronounced: the difference between incidence densities expressed per 1,000 patient-days compared with 1,000 catheter-days at risk was 4 -fold. However, the difference between rates determined on the basis of device-days and device-days at risk was not pronounced. Not only does the denominator influence risk estimates, but the numeratorand hence the definition of the outcome variable-may have a similar effect among neonates. Including laboratory-confirmed bloodstream infections exclusively in a surveillance or adding cases with clinical sepsis results in considerable differences in rates. The sensitivity of blood culture in neonates is low, and the CDC definitions of clinical sepsis leave room for interpretation. Considering only laboratory-confirmed bacteremia is likely to underestimate the true rate, whereas including clinical sepsis in the surveillance program is likely to overestimate the rate. ${ }^{23-26}$ Thus, the true rate probably cannot be determined until more specific markers of neonatal bloodstream infections become available. At a time of public reporting of nosocomial infections, hospitals are tempted to report only laboratory-confirmed infections. However, given the low sensitivity of blood cultures in neonates, such reporting may underestimate central line-associated bloodstream infection rates unacceptably, as was also evidenced by our study.

Studies and HAI surveillance programs conducted among neonates use different formats for data reporting. The US National Healthcare Safety Network (NHSN) reports laboratory-confirmed bloodstream infections and clinical sepsis and stratifies data into 5 birth weight categories, whereas the German Hospital Infection Surveillance System (KISS) stratifies into 2 birth weight categories. ${ }^{39,40}$ Furthermore, the US NHSN distinguishes central from umbilical catheters in its latest report. ${ }^{39}$ Such differences make comparisons and benchmarking difficult, if not impossible. Basically, a center has to decide which surveillance method to use and whether benchmarking with US or European data is preferred. Our detailed and individualized data collection is quite unique and allowed us to compare our data with both the US NHSN and German KISS reports (Table 5). As is shown, our CLABICS incidence 
densities were similar to the German KISS data $(10.6[95 \% \mathrm{CI}$, 8.6-12.0] vs 11.1 [95\% CI, 10.4-11.9] episodes per 1,000 catheter-days). However, our rates were consistently higher for central lines, for umbilical lines, and across all birth weight categories other than $2,500 \mathrm{~g}$ or higher when compared with the NHSN (Table 5). There is no explanation for why European rates are so much higher than US rates, but it is noteworthy that not all recent US studies have produced data that are in line with the current (and rather low) NHSN data, ${ }^{39}$ and data from these studies mirror our results. ${ }^{36,37}$

A limitation of our study is the lack of data on peripheral lines. Although no evidence to suggest that PICC use increases the risk of adverse events relative to peripheral lines was found, ${ }^{41}$ it would have been useful to consider our data in the context of all vascular access devices, and more information on whether peripheral lines could replace PICCs is needed.

In conclusion, the present study has shown that catheter dwell time is a risk factor for CLABICS in neonates with umbilical catheters and PICCs during the first 7 days of their use, but not thereafter. Considering the median dwell time of 7 days, routine PICC replacement is not advisable, in light of our findings. However, a firm recommendation about the dwell time of PICCs in neonates needs confirmation by additional studies. Individualized catheter surveillance allows benchmarking with different surveillance systems and detection of unanticipated risk factors. Such detailed results on catheter type provide optimal feedback and enable tailoring of prevention measures that account for specific local shortcomings.

\section{ACKNOWLEDGMENTS}

We thank the teams of the neonatal unit and the pediatric intensive care unit of the University of Geneva Hospitals for their support and Rosemary Sudan for editorial assistance.

Financial support. This study was conducted as a qualitative research project and was funded by the University of Geneva Hospitals.

Potential conflicts of interest. All authors report no conflicts of interest relevant to this article.

Address reprint requests to Didier Pittet, MD, MS, University of Geneva Hospitals and Faculty of Medicine, 4 rue Gabrielle Perret-Gentil, 1211 Genève 14, Switzerland (didier.pittet@hcuge.ch).

Presented in part at the 48th Annual Interscience Conference on Antimicrobial Agents and Chemotherapy; Washington, DC; October 2008 (Abstract K-3419).

\section{REFERENCES}

1. Brady MT. Health care-associated infections in the neonatal intensive care unit. Am J Infect Control 2005;33:268-275.

2. Harbarth S, Pittet D. The intensive care unit. In: Jarvis WR, ed. Bennett and Brachman's Hospital Infections. Philadelphia, PA: Lippincott Williams \& Wilkins, 2007:373-393.

3. Stover BH, Shulman ST, Bratcher DF, Brady MT, Levine GL, Jarvis WR. Nosocomial infection rates in US children's hospitals' neonatal and pediatric intensive care units. Am J Infect Control 2001;29:152-157.

4. Hentschel J, Brungger B, Studi K, Muhlemann K. Prospective surveillance of nosocomial infections in a Swiss NICU: low risk of pneumonia on nasal continuous positive airway pressure? Infection 2005;33:350-355.

5. Schwab F, Geffers C, Barwolff S, Ruden H, Gastmeier P. Reducing neonatal nosocomial bloodstream infections through participation in a national surveillance system. J Hosp Infect 2007;65:319-325.

6. Pittet D, Harbarth S, Ruef C, et al. Prevalence and risk factors for nosocomial infections in four university hospitals in Switzerland. Infect Control Hosp Epidemiol 1999;20:37-42.

7. Sax H, Hugonnet $S$, Harbarth $S$, Herrault $P$, Pittet $D$. Variation in nosocomial infection prevalence according to patient care setting: a hospitalwide survey. $J$ Hosp Infect 2001;48:27-32.

8. Pittet D. Nosocomial bloodstream infections. In: Wenzel RP, ed. Prevention and Control of Nosocomial Infections. Baltimore, MD: Lippincott Williams \& Wilkins, 1997;711-769.

9. Contreras-Cuellar GA, Leal-Castro AL, Prieto R, Carvajal-Hermida AL. Device-associated infections in a Colombian neonatal intensive care unit. Rev Salud Publica (Bogota) 2007;9:439-447.

10. El-Nawawy AA, Abd El-Fattah MM, Metwally HA, Barakat SS, Hassan IA. One year study of bacterial and fungal nosocomial infections among patients in pediatric intensive care unit (PICU) in Alexandria. $J$ Trop Pediatr 2006;52:185-191.

11. Balkhy HH, Cunningham G, Chew FK, et al. Hospital- and communityacquired infections: a point prevalence and risk factors survey in a tertiary care center in Saudi Arabia. Int J Infect Dis 2006;10:326-333.

12. Couto RC, Carvalho EA, Pedrosa TM, Pedroso ER, Neto MC, Biscione FM. A 10-year prospective surveillance of nosocomial infections in neonatal intensive care units. Am J Infect Control 2007;35:183-189.

13. Elward AM, Fraser VJ. Risk factors for nosocomial primary bloodstream infection in pediatric intensive care unit patients: a 2-year prospective cohort study. Infect Control Hosp Epidemiol 2006;27:553-560.

14. Mireya UA, Marti PO, Xavier KV, Cristina LO, Miguel MM, Magda CM. Nosocomial infections in paediatric and neonatal intensive care units. $J$ Infect 2007;54:212-220.

15. Raka L, Zoutman D, Mulliqi G, et al. Prevalence of nosocomial infections in high-risk units in the university clinical center of Kosova. Infect Control Hosp Epidemiol 2006;27:421-423.

16. Perlman SE, Saiman L, Larson EL. Risk factors for late-onset health careassociated bloodstream infections in patients in neonatal intensive care units. Am J Infect Control 2007;35:177-182.

17. Posfay-Barbe KM, Zerr DM, Pittet D. Infection control in paediatrics. Lancet Infect Dis 2008;8:19-31.

18. Zingg W, Posfay-Barbe KM, Pittet D. Healthcare-associated infections in neonates. Curr Opin Infect Dis 2008;21:228-234.

19. Pessoa-Silva CL, Hugonnet S, Pfister R, et al. Reduction of health care associated infection risk in neonates by successful hand hygiene promotion. Pediatrics 2007;120:e382-e390.

20. International Neonatal Network. The CRIB (clinical risk index for babies) score: a tool for assessing initial neonatal risk and comparing performance of neonatal intensive care units. Lancet 1993;342:193-198.

21. Apgar V. A proposal for a new method of evaluation of the newborn infant. Curr Res Anesth Analg 1953;32:260-267.

22. Eggimann P, Harbarth S, Constantin MN, Touveneau S, Chevrolet JC Pittet D. Impact of a prevention strategy targeted at vascular-access care on incidence of infections acquired in intensive care. Lancet 2000;355: 1864-1868.

23. Connell TG, Rele M, Cowley D, Buttery JP, Curtis N. How reliable is a negative blood culture result? volume of blood submitted for culture in routine practice in a children's hospital. Pediatrics 2007;119:891-896.

24. Hugonnet S, Sax H, Eggimann P, Chevrolet JC, Pittet D. Nosocomial bloodstream infection and clinical sepsis. Emerg Infect Dis 2004;10:76-81.

25. Garner JS, Jarvis WR, Emori TG, Horan TC, Hughes JM. CDC definitions for nosocomial infections, 1988. Am J Infect Control 1988;16:128-140.

26. Horan TC, Andrus M, Dudeck MA. CDC/NHSN surveillance definition of health care-associated infection and criteria for specific types of infections in the acute care setting. Am J Infect Control 2008;36:309-332.

27. Eggimann P, Hugonnet S, Sax H, Touveneau S, Chevrolet JC, Pittet D. 
Ventilator-associated pneumonia: caveats for benchmarking. Intensive Care Med 2003;29:2086-2089.

28. Zingg W, Imhof A, Maggiorini M, Stocker R, Keller E, Ruef C. Impact of a prevention strategy targeting hand hygiene and catheter care on the incidence of catheter-related bloodstream infections. Crit Care Med 2009; 37:2167-2173.

29. Zingg W, Sax $\mathrm{H}$, Inan $\mathrm{C}$, et al. Hospital-wide surveillance of catheterrelated bloodstream infection: from the expected to the unexpected. $J$ Hosp Infect 2009;73:41-46.

30. Freeman J, Goldmann DA, Smith NE, Sidebottom DG, Epstein MF, Platt R. Association of intravenous lipid emulsion and coagulase-negative staphylococcal bacteremia in neonatal intensive care units. $N$ Engl J Med 1990;323:301-308.

31. Holmes A, Dore CJ, Saraswatula A, et al. Risk factors and recommendations for rate stratification for surveillance of neonatal healthcareassociated bloodstream infection. $J$ Hosp Infect 2008;68:66-72.

32. Nagata $E$, Brito AS, Matsuo T. Nosocomial infections in a neonatal intensive care unit: incidence and risk factors. Am I Infect Control 2002; 30:26-31.

33. Chathas MK, Paton JB, Fisher DE. Percutaneous central venous catheterization: three years' experience in a neonatal intensive care unit. $\mathrm{Am}$ J Dis Child 1990;144:1246-1250.

34. Clark R, Powers R, White R, Bloom B, Sanchez P, Benjamin DK Jr. Prevention and treatment of nosocomial sepsis in the NICU. J Perinatol 2004;24:446-453.

35. Stoll BJ, Hansen N, Fanaroff AA, et al. Late-onset sepsis in very low birth weight neonates: the experience of the NICHD Neonatal Research Network. Pediatrics 2002;110:285-291.

36. Smith PB, Benjamin DK Jr, Cotten CM, et al. Is an increased dwell time of a peripherally inserted catheter associated with an increased risk of bloodstream infection in infants? Infect Control Hosp Epidemiol 2008;29: 749-753.

37. Hoang V, Sills J, Chandler M, Busalani E, Clifton-Koeppel R, Modanlou HD. Percutaneously inserted central catheter for total parenteral nutrition in neonates: complications rates related to upper versus lower extremity insertion. Pediatrics 2008;121:e1152-e1159.

38. Ben Jaballah N, Bouziri A, Mnif K, Hamdi A, Khaldi A, Kchaou W. Epidemiology of hospital-acquired bloodstream infections in a Tunisian pediatric intensive care unit: a 2-year prospective study. Am J Infect Control 2007;35:613-618.

39. Edwards JR, Peterson KD, Andrus ML, Dudeck MA, Pollock DA, Horan TC. National Healthcare Safety Network (NHSN) report, data summary for 2006 through 2007, issued November 2008. Am J Infect Control 2008; 36:609-626.

40. Geffers C, Baerwolff S, Schwab F, Gastmeier P. Incidence of healthcareassociated infections in high-risk neonates: results from the German surveillance system for very-low-birthweight infants. J Hosp Infect 2008; 68:214-221.

41. Ainsworth SB, Clerihew L, McGuire W. Percutaneous central venous catheters versus peripheral cannulae for delivery of parenteral nutrition in neonates. Cochrane Database Syst Rev 2007:CD004219. 